Orbis Tertius, vol. XXVI, nº 34, e217, noviembre 2021 - abril 2022. ISSN 1851-7811

Universidad Nacional de La Plata

Facultad de Humanidades y Ciencias de la Educación

Centro de Estudios de Teoría y Crítica Literaria

\title{
La historiografía en los registros de visita: fray Alonso Ponce
}

\author{
Historiography in Visita records: Fray Alonso Ponce
}

\author{
Patricia Escandón \\ patricia.escandon@gmail.com \\ Centro de Investigaciones sobre América Latina y el \\ Caribe. Universidad Nacional Autónoma de México, \\ México
}

Recepción: 15 Abril 2021

Aprobación: 08 Agosto 2021

Publicación: 01 Noviembre 2021

Cita sugerida: Escandón, P. (2021). La historiografía en los registros de visita: fray Alonso Ponce. Orbis Tertius, 26(34), e217. https://doi.org/10.24215/18517811e217

\begin{abstract}
Resumen: Aparte de constituir informes de carácter oficial, la documentación generada por la visita del comisario franciscano Alonso Ponce (1584-1589) a su orden en Nueva España es una cala profunda en la sociedad y la estructura gubernativa finiseculares del reino. En el registro de la visita, escrito por el secretario fray Antonio de Ciudad Real, y en algunos expedientes remitidos al Consejo de Indias, tanto por el comisario como por sus enemigos, se delinean con nitidez la naturaleza de los conflictos de poder entre los altos dignatarios civiles y eclesiásticos, las alianzas y confrontaciones entre distintas agencias locales, así como el cambio de orientación en el tipo de pastoral que desarrollaban las órdenes regulares en el último tercio del XVI.
\end{abstract}

Palabras clave: Fray Alonso Ponce, Fray Antonio de Ciudad Real, Comisarios franciscanos, Nueva España.

\begin{abstract}
Besides acting as official reports, documentation generated after the Franciscan commissary Fray Alonso Ponce's (1584-1589) Visita to the Order in New Spain is an indepth account on the kingdom's society and governmental structure towards the end of the century. In the records, written by his secretary Fray Antonio de Ciudad Real, and in some documentation submitted to the Consejo de Indias (Council of the Indies) both by the commissary and by his enemies, the nature of power conflicts between high civil and ecclesiastical dignitaries, the alliances and confrontations among different local agencies, and a reorientation in the regular order's pastoral ministry over the last months of the sixteenth century can be clearly read.
\end{abstract}

Keywords: Fray Alonso Ponce, Fray Antonio de Ciudad Real, Franciscan Commissaries, New Spain.

\section{LOS MECANISMOS DE CONTROL DEL GOBIERNO INDIANO}

Los mayores retos del poder castellano en sus reinos y provincias de ultramar los constituían lo vasto y remoto de aquellos territorios, así como la exasperante dilación de las comunicaciones por vía marítima. Desde luego, no tenía sentido que las provisiones y decisiones urgentes en materia política y administrativa las tomasen en la península la Corona o su Consejo de Indias; estas tenían que ser forzosamente delegadas en representantes civiles y eclesiásticos, que sólo después de decidir e instrumentar resoluciones, turnaban informes de su actuación a la metrópoli. De ahí que a las autoridades indianas se les hubiese concedido una 
amplia gama de atribuciones y facultades, que si bien por una parte resultaban útiles en cuanto a la adopción de medidas expeditas para atender los problemas, por la otra se prestaban a extralimitaciones o abusos de los funcionarios regios investidos con tanto poder.

En consecuencia, y a fin de evitar o remediar tales eventualidades, los soberanos de Castilla también se vieron precisados a establecer diferentes formas de vigilancia y contención de las labores de sus delegados. Así, al tiempo que con una mano aflojaban, con la otra acortaban la rienda para intentar mantener un complejo y siempre frágil equilibrio en el desempeño de las instancias gubernativas y judiciales de América.

Desde el punto de vista jurídico, los dos mecanismos básicos del control regio sobre personas e instituciones en Indias fueron: el juicio de residencia y la visita. El primero era un procedimiento judicial público al que se sometía el funcionario que terminaba su encargo y en el que podían testificar, a favor en contra, todos aquellos que habían estado bajo su autoridad; al momento del juicio, el "residenciado" ya había cesado en sus funciones. La segunda, en cambio, era una inspección, más o menos secreta, a cargo de una autoridad específicamente nombrada. Esta podía darse en cualquier oportunidad que se suscitara una situación inquietante, anómala o de emergencia y los sujetos a ella continuaban en sus puestos durante el transcurso de la visita.

Tales dispositivos fiscalizadores del gobierno civil, tenían en el eclesiástico una suerte de contrapartidas, sobre todo en las llamadas visitas episcopales y en las de órdenes religiosas. Y, en determinadas circunstancias, también en los juicios de residencia a ciertos prelados de la Iglesia. No obstante, las visitas eclesiásticas no necesariamente revestían propósitos fiscalizadores o punitivos, aunque siendo un dispositivo de control, sí podían incluirlos. Tanto desde el punto de vista canónico como desde el del Regio Patronato Indiano, las visitas pastorales constituían una obligación de los obispos, quienes tenían que cerciorarse personalmente de los avances, desafíos y problemas de sus jurisdicciones, así como de la actuación del clero a su cargo y de la debida atención de la feligresía (Leal Lobón, 2000, p. 465).

En las Indias las órdenes religiosas (o clero regular) no estaban directamente sujetas a la autoridad de los obispos, salvo cuando ejercían funciones de curas. Su cadena de mando iniciaba en un ministro general, residente en Roma, continuaba en un comisario general de Indias, asentado en Madrid y se escindía en tierras americanas en dos grandes jefaturas: la comisaría de Nueva España en el norte y la del Perú en el sur (Arroyo, 1952, pp. 129-172). Estos últimos eran, por así decirlo, los “inspectores en jefe” de unas 18 provincias o circunscripciones dispersas por todo el continente; al comisario novohispano, que vivía en la ciudad de México, le competía la supervisión de las seis del virreinato novohispano, la de Guatemala, Nicaragua, La Florida y Filipinas; al del Perú, asentado en Lima, le competían todas las restantes que caían en territorio sudamericano.

A este par de dignatarios incumbía la atención de los negocios importantes de la orden en los respectivos virreinatos y sus distritos, además de tener el encargo de hacer visitas a las provincias bajo su mando, a fin de cerciorarse y garantizar que sus súbditos cumplieran sus deberes y que la administración espiritual de la grey bajo su cargo fuese la correcta. Facultades exclusivas suyas eran convocar y presidir las asambleas o "capítulos" provinciales trianuales de cada demarcación, resolver controversias internas, trasladar por razones de peso a los frailes de una provincia a otra y aun castigar o excomulgar a los religiosos incorregibles. Lo único que no podían hacer era revocar el mandato de los padres provinciales, lo que era prerrogativa del ministro general de la orden.

Los comisarios solían durar en funciones unos seis años - que a veces se prolongaban- y al término de su gestión, ellos mismos eran sometidos a juicios de residencia, que habitualmente instrumentaban sus sucesores en el cargo. Estos procesos no eran abiertos al público, aunque sí testificaban en él los frailes que habían estado bajo la autoridad del comisario saliente. Con tales dispositivos, la orden franciscana y el soberano de Castilla intentaban asegurarse, por un lado, de que las jurisdicciones franciscanas de América fueran debidamente gobernadas e inspeccionadas y también de que, al final, se le tomaran al supervisor mismo cuentas de sus actos y determinaciones (Arroyo, 1950, pp. 14-16). 


\section{LA TEMPESTUOSA VISITA DE UN COMISARIO}

En septiembre de 1584 arribó a Nueva España su $15^{\circ}$ comisario general, en la persona de fray Alonso Ponce. Aparejadas a las consignas reglamentarias de su cargo ya mencionadas, como presidir las elecciones trianuales de autoridades en las provincias y visitar en persona su amplísima jurisdicción, venían instrucciones expresas del ministro general franciscano de procurar la concordia, no sólo entre sus súbditos de hábito, sino también con los obispos y con los representantes del poder real. A su llegada, Ponce tomó por secretario a un joven fraile manchego que servía en Yucatán, fray Antonio de Ciudad Real. Así que a lo largo de los siguientes cinco años, ambos recorrieron poco más de $12 \mathrm{mil} \mathrm{km}$, visitaron las seis provincias novohispanas e inspeccionaron 166 conventos, desde el lejano norte de la Nueva España, en Tepic, Nayarit, hasta la ciudad de Granada, en Nicaragua.

Sin embargo, en contra de lo que sancionaban sus órdenes, la gestión, estancia y extenso periplo de Ponce estuvieron plagados de dificultades y pleitos. Al principio, naturalmente, fue reconocido por todos los franciscanos de Nueva España como su superior; sin embargo, a poco de haberse instalado en la ciudad de México, cabeza de la provincia del Santo Evangelio, empezaron los sinsabores. Antes de transcurrido un año, se había enemistado con los religiosos de la capital, en especial con el padre provincial de México, fray Pedro de San Sebastián y su definitorio (es decir, su cuerpo asesor); todos ellos acabaron por desconocer su autoridad y le declararon una encarnizada guerra. En ocasión de una salida suya a Michoacán en 1586, le obstaculizaron el regreso a la capital del reino y lo malquistaron con el nuevo virrey, marqués de Villamanrique; luego, mientras Ponce continuaba sus visitas por otros rumbos, implicaron en el embrollo a algunas órdenes más y a miembros del clero secular, con lo que el pleito se generalizó y enconó.

Hubo intentos de mediación, pero fray Alonso era un funcionario celoso y obstinado, en tanto que su principal enemigo, el provincial vizcaíno de México, padre San Sebastián, hacía gala de orgullo y prepotencia desmedidos, de tal suerte que todos los esfuerzos de los mediadores y conciliadores fracasaron. En cambio, uno y otro remitieron abundantes cartas acusatorias a Su Majestad y al Consejo de Indias, ${ }^{1}$ aunque la disputa no quedó solo en el papel. Cuando los franciscanos descalzos de San Cosme dieron refugio al acosado comisario, sus hermanos del convento grande de México se violentaron y los atacaron con palos y espadas (Reyes García, 1971, pp. 335, 347). Más adelante le orquestaron un gran motín y alboroto en el convento de Texcoco y Ponce acabó por fulminar excomuniones contra los insubordinados.

En 1587, las intrigas y tensiones llegaron a un punto sin retorno. Estando el comisario en el convento franciscano de Santa Bárbara, en Puebla, los alguaciles del virrey lo sacaron a rastras y lo pusieron en camino a Veracruz, con una orden de destierro, a pesar de las airadas protestas del obispo local que defendía la inmunidad del clérigo. Desde San Juan de Ulúa lo embarcaron rumbo a La Habana, con intención manifiesta de remitirlo desde ahí de vuelta a España. Empero, fray Alonso acabó volviendo a Yucatán, donde esperó el arribo de su sustituto, el padre San Cebrián; finalmente, este le instruyó un juicio de residencia del que salió bien librado. Y, en cambio, envió a seis de sus adversarios a la península, para que fuesen juzgados allá (Morales Valerio, 1988, pp. 678-682; Morales Valerio, 1973, pp. 63-66; Ciudad Real, 1976, pp. IX-XII).

Que el ex comisario Ponce fue totalmente exonerado de culpa por los escándalos, lo demuestra el que en 1589, a su regreso a España, se le nombrara guardián del importante convento de Alcalá de Henares y, más adelante, confesor de un Grande de España, el duque del Infantado. Fray Alonso murió tranquilamente en el convento franciscano de Guadalajara a fines del siglo XVI.

\section{LO INSTITUCIONAL Y LO INCIDENTAL}

Por lo que se ha dicho, y pese a todo, fray Alonso Ponce cumplió una visita comisarial extraordinaria, ya que no se sabe de ninguna otra, previa o posterior, de semejantes alcances territoriales. Pero de ella poco se 
conocería, de no haber sido por el papel crucial que desempeñó su eficientísimo secretario, fray Antonio de Ciudad Real.

Como lo preveían sus funciones, fray Antonio llevó un escrupuloso diario de los viajes y actividades de Ponce, lo que teóricamente debía haber constituido un escueto informe oficial, en principio, dirigido a las autoridades franciscanas de Madrid y en segundo término, a la Corona misma. Empero sucedía que, de tiempo atrás el joven fraile tenía sus inquietudes y proyectos propios respecto de la realidad de las Indias. Por noticias que dio otro religioso, amigo y compañero suyo en Yucatán, fray Bernardo de Lizana, consta que fray Antonio trabajaba ya hacía rato en un tratado relativo a las tierras y pueblos yucatecos. Es evidente que al ser designado acompañante del nuevo comisario, Ciudad Real simplemente ensanchó la perspectiva temáticogeográfica para incluir en su plan de escritura al espectro completo que encontró en su recorrido novohispano.

Sin embargo, lo cierto es que el secretario sólo pudo poner manos a la obra cuando retornó a la península con el padre Ponce. En el convento de Alcalá y acaso también en el de Guadalajara organizó sus notas, las dispuso cronológicamente y se dio a la tarea de preparar los más de 260 folios en los que distribuyó 180 capítulos que daban cuenta de las peripecias de la visita de su superior y de otras muchas cuestiones. El título que la posteridad dio a este volumen fue Tratado curioso y docto de las grandezas de la Nueva España. Relación breve y verdadera de algunas cosas de las muchas que sucedieron a padre fray Alonso Ponce en las provincias de la Nueva España siendo comisario general de aquellas partes. ${ }^{2}$

En cuanto a la visita en sí y en punto a estadísticas, habrán de incluirse, en principio, todas las que proporcionó referentes a los conventos, frailes y pueblos de doctrina de las vastas provincias franciscanas de México, Michoacán, Jalisco, Yucatán y Guatemala, entre otros sitios. Las distancias que separaban a una fundación de otra, las características de las casas, el número de residentes y el estado de la administración espiritual por localidad están también consignadas en detalle y en el estricto orden cronológico en el que se produjo cada inspección.

Según puede deducirse por la estructura general de la obra, Ciudad Real se sirvió del modelo de cuestionarios diseñados por el visitador del Consejo de Indias, don Juan de Ovando, que ya circulaban desde 1577 y cuya pretensión era recabar datos puntuales sobre los recursos físicos y humanos de todos los territorios imperiales. La compilación de estos documentos es la masa informativa que hoy se conoce como las Relaciones geográficas de Felipe II.

Cabe señalar, empero, que esto tenía algunos antecedentes. En 1570, la provincia franciscana de San José de Yucatán, como todas las demás del reino, había recibido una real cédula suscrita en Madrid, el 23 de enero de 1569 (Solano, 1988, pp. 11-12), en que se le requería que proporcionase informes sobre el número de religiosos que servían las doctrinas, la población que había en estas y otros muchos detalles. La orden regia se fundamentaba en un listado temático que había elaborado también el visitador Ovando para recoger materiales sobre la administración eclesiástica. Aunque hoy se desconoce el paradero del documento con el que respondió la provincia yucateca, es seguro que hubiera quedado una copia de ella en el archivo del convento de Mérida y no cabe duda de que el joven padre Ciudad Real, que fue nombrado secretario del padre provincial yucateco en 1576, debía estar familiarizado con esta documentación. Por ello no sorprende que en su ulterior relación de la visita del comisario Ponce hubiera considerado algunas partes de dicho esquema, organizado por rubros.

Aunque ciertamente, fray Antonio sólo se ciñó de manera parcial a él, pues el resto de su relato discurre de manera libre. Pero en cuanto a algunos de los capítulos de las "Instrucciones" del cuestionario ovandino, Ciudad Real aportó referencias sobre el clima, la topografía, la hidrografía y la elevación de todas las regiones visitadas, igualmente respecto de los cultivos y la fauna. Tratándose de pueblos indígenas, dio pormenores sobre su densidad demográfica, lenguas, gobierno, creencias, costumbres, trajes y alimentación; en materia de asentamientos de españoles registró ubicación, distancias, número de habitantes, infraestructura, comercio y otras actividades productivas, amén de puntualizaciones respecto a parroquias y obispados locales. 
Como se entenderá y dada la gran cantidad de áreas que abarcó la visita, estos testimonios ocupan una parte muy considerable del manuscrito; no obstante, el resto del contenido, es decir, todo aquello que no reviste un carácter de informe institucional, es, según he afirmado, una pintura libre, original y a ratos divertida de la sociedad novohispana finisecular y de las tensiones presentes entre algunos de sus sectores más encumbrados. A esto es a lo que denomino la parte incidental del Tratado de Ciudad Real que es, si cabe, mucho más interesante que la otra.

Empecemos por las contrariedades que experimentó el comisario Ponce con sus hermanos de hábito. La raíz del problema era que a mediados de los años 80 del XVI el poder en la provincia franciscana de México constituía virtualmente un monopolio de los llamados "hijos de provincia", gente nacida en la vieja España que había tomado los hábitos en la nueva y que estaba perfectamente compenetrada de los intereses locales, intra y extra conventuales. Estos mantenían una lucha y competencia acérrima por el control político con los frailes profesos en la península, para lo cual se apoyaban en los jóvenes religiosos criollos, siempre que se trataba de votar en las elecciones para proveer cargos (Bacicalupo, 1981, pp. 67-70).

Sin que pudiera decirse que la postura del comisario Ponce fuese abiertamente pro-española, es verdad que en mucho ponía límites a las pretensiones omnímodas del provincial mexicano, fray Pedro de San Sebastián y su numeroso bando de hijos de provincia y de americanos; igualmente lo es que no siempre autorizó la elección de frailes jóvenes para los puestos de mayor responsabilidad y que llegó a externar algunas críticas sobre la conducta de los hermanos nacidos en Indias.

Tales enfrentamientos, que relató vívidamente el secretario Ciudad Real, reflejan una pugna por la hegemonía que, aparentemente sería la de una facción "metropolitana" contra una "indiana”, toda vez que la presencia de un superior peninsular que tomaba decisiones sobre la provisión de cargos y otros asuntos, fue considerada por las jefaturas franciscanas criollizadas y criollas como una inadmisible intrusión en el manejo de la provincia de México (Rubial, 2001, pp. 67-71). De paso, habrá que decir que figuras eminentísimas de la orden, como los historiadores Jerónimo de Mendieta y fray Bernardino de Sahagún tomaron parte en estas trifulcas. Mendieta para intentar reconciliar a las banderías en pugna (García Icazbalceta, 1892, II, pp. 54-57) y Sahagún, que era definidor, tuvo una posición más errática, que ora favorecía al provincial San Sebastián y a sus seguidores, ora al comisario y a los que le eran afines (León Portilla, 1999, pp. 190-199). Empero, y aunque los bandos se autoproclamaban de "gachupines" y de "criollos", los conflictos de fondo no tenían tanto que ver con el lugar de nacimiento de sus militantes y sí mucho con las estrategias de grupos corporativos o agencias formadas bajo esos títulos, que presionaban y luchaban entre sí por imponer sus aspiraciones, agendas y proyectos políticos particulares.

Por otra parte, la obra de Ciudad Real deja ver claramente las dificultades inherentes al cambio de modelo pastoral que se estaba operando en el seno de la orden franciscana. A estas alturas, mal o bien evangelizados, todos los indígenas del centro de México ya habían recibido la fe, de modo que el sistema de doctrina rural entre los indios -característico de los primeros tiempos- perdía peso rápidamente frente al despuntar de la importancia de los grandes conventos urbanos. La asignación de doctrineros en pueblos indígenas se hacía entre frailes del "común", cuyos deberes se limitaban a los de un cura párroco: administrar sacramentos y reforzar la fe entre su feligresía indígena. En cambio, los puestos directivos, de mayor responsabilidad o lustre (provincial, definidor, predicador de españoles, etc.) se reservaban para los religiosos mejor relacionados socialmente, esto es, aquellos cuya familia o allegados tenían papeles prominentes en la administración pública o en la vida comercial del reino. Según la versión de Ponce -que transcribe su secretario- buena parte de estos "favoritos" o "agraciados" eran frailes criollos, jóvenes, mal preparados y no siempre de buenas pautas morales. Esto mismo lo escribía Ponce al virrey Villamanrique en una carta:

Los frailes de esta tierra tienen mucha mano en ella (...). Es muy injusto y fuera de buena razón y gobierno tengan mano y autoridad para dar a mira los bienes destos pobres naturales, y de su sudor y sangre hacer presentes a sus padres y parientes y amigos con que los sustenten y tengan a su voluntad (Ponce, 1586). 
Un tercer aspecto que apunta entre las líneas del Tratado es la confluencia o alianza de intereses entre la figura virreinal y la Audiencia, por un lado y los mendicantes locales por la otra, esto en detrimento del papel de los visitadores y comisarios recién llegados de la metrópoli. Además de lo que asentó Ciudad Real, el hecho encuentra confirmación en la correspondencia de Villamanrique a Felipe II; en su carta del 19 de diciembre de 1588, tildaba abiertamente a Ponce de ser "duro e inobediente" y poco dado a los métodos pacíficos para la resolución de conflictos, añadía que, a pesar de los apercibimientos de la Real Audiencia para que levantase las excomuniones contra los graves padres de la provincia de México, su obstinación era inquebrantable, razón por la que lo había desterrado (Villamanrique, 1588). Quizá su dictamen no era tan preciso ni objetivo, pues corría fama de que el marqués era muy simpatizante de las órdenes religiosas (Borges Morán, 1992, I, pp. 689-690), pero no tanto de los prelados, seculares o regulares, de la Iglesia.

No puede llamar a sorpresa este género de sociedad entre el mayor dignatario del reino y su alto tribunal de justicia con un grupo o grupos locales de agenda propia. El virrey o los oidores que no se aviniesen a negociar algún tipo de acuerdo con los poderosos de la tierra, no podían alentar expectativas, ya no digamos de mantener una gestión más o menos tersa, pero ni siquiera de terminar el periodo completo de su régimen, según lo demostraría más de un ejemplo (como el triste caso del marqués de Gelves entre 1622 y 1624). Así que a pesar de la legislación indiana y de las reiteradas órdenes y provisiones regias en contrario, los funcionarios civiles avecindados en Indias no tardaban mucho en anudar lazos con individuos, clanes o redes indianas que acaparaban dinero y prestigio; a veces emparentaban con ellos o emprendían negocios conjuntos, las más aceptaban dádivas y beneficios y solicitaban créditos o favores. Los altos prelados eclesiásticos tampoco tenían las manos enteramente limpias, pues no era excepcional que colocaran a sus clientelas o allegados en puestos apetecibles y que, de vez en cuando, incluso montaran lucrativas empresas (Ruiz Medrano, 1992, pp. 63-83).

Con semejantes prácticas, como se entiende, estos dignatarios no podían dejar de entretejer sus intereses socioeconómicos personales con el funcionamiento del orden político y administrativo del reino, lo que a todas luces resultaba ser incompatible con las instrucciones o políticas de los visitadores recién llegados y, por tanto, ayunos del entendimiento de los entramados, pactos y obligaciones que ya estaban bien establecidos en la tierra.

Una cuarta faceta que aflora entre los accidentados episodios del relato de fray Antonio son las ríspidas relaciones y, de vez en vez, incluso los choques frontales que podían darse entre los virreyes o Audiencias y los obispos a causa de la interpretación y alcances del Regio Patronato, y de las obligaciones y facultades canónicas de los prelados (Ricard, 1986, p. 378). La aprehensión del padre Ponce en un convento poblano dio ocasión a que el titular de la diócesis de Puebla-Tlaxcala, don Diego Romano y Gobea, pusiera el grito en el cielo y se querellara contra el virrey, tanto porque se atropellaba con indecencia el fuero de un ministro eclesiástico - pues tal era el comisario- como porque el violento procedimiento aplicado por la justicia civil se había llevado a cabo en un lugar consagrado y, en teoría, inviolable. La respuesta del marqués de Villamanrique a esta queja fue desdeñosa, pues simplemente alegó haber actuado en ejercicio de sus facultades como vicepatrono de la Iglesia. Y, por cierto, tan regalista resultó este dignatario que, al término de su gestión, el Tribunal del Santo Oficio de México le siguió causa por abuso de funciones, puesto que osó interceptar y requisar la correspondencia inquisitorial. ${ }^{3}$

Pero antes de cerrar estas breves reflexiones en torno al Tratado de fray Antonio de Ciudad Real que, como se ha visto, trasciende el carácter de un mero registro de visita, para convertirse en fuente primordial de la historia social y política de la Nueva España de las postrimerías del XVI, quizá convenga satisfacer un poco la curiosidad que pueda haberse suscitado sobre el destino final de los protagonistas de esta historia de escándalos.

Como ya se ha señalado, el ex comisario Alonso Ponce murió en paz, en el convento de Guadalajara a fines de siglo. Cuando esto aconteció, su secretario, fray Antonio de Ciudad Real, retornó a su querido Yucatán, donde acabó sus días muchos años después. 
En cuanto a los revoltosos frailes del Santo Evangelio: el ex provincial fray Pedro de San Sebastián y cuatro de sus exaltados compañeros -pues uno de ellos jamás llegó a la península, por haberse fingido enfermo en La Habana- recibieron castigos leves. No tardaron demasiado en volver a su provincia de México, donde a la larga recuperaron sus cargos y posiciones.

En 1590, a la llegada del nuevo virrey don Luis de Velasco, el saliente, marqués de Villamanrique, fue sometido a juicio de residencia. El juez comisionado para la conducción del proceso fue, ni más ni menos que su gran enemigo, el obispo de Puebla-Tlaxcala, don Diego Romano. Naturalmente, este le cobró las pasadas afrentas, que no solo tenían que ver con los incidentes de la visita de Ponce en la ciudad angelopolitana, sino con otras diferencias que había tenido el virrey con el episcopado novohispano en general y en particular con el arzobispo de México, don Pedro Moya de Contreras. A la postre, y a lo largo de dos años, Romano logró acumular en el expediente más de 340 cargos en contra de Villamanrique; desde luego, el juicio culminó en un fallo condenatorio de su gestión. ${ }^{4}$ El marqués volvió a España caído en desgracia, le embargaron bienes y se le exilió de la corte; sin embargo, a la vuelta de nueve años fue rehabilitado por el rey Felipe III. ${ }^{5}$

En suma, si bien el alboroto resultante de la visita del comisario fray Alonso Ponce alcanzó grandes proporciones, al grado de que por algunos años se convirtió en la comidilla general de la población novohispana y sobrevinieron de ahí juicios y puniciones, finalmente, todo acabó en agua de borrajas, incluso para los hallados culpables.

Por ello, aún campea una última pregunta ¿qué habremos de concluir entonces respecto de los mecanismos del control de la Corona sobre instituciones e individuos? ¿Diremos que fueron fallidos, que eran sólo trampantojos para dar visos de una supervisión y una administración de justicia regios que en realidad eran inexistentes? Dudosamente. Con todas sus imperfecciones y con sus resultados a veces frustráneos, las visitas y los juicios de residencia cumplieron invariablemente un papel disuasorio del ejercicio excesivo de atribuciones por parte de los servidores del rey. Estos, junto con el empalme o indistinción deliberados de las facultades gubernativas y judiciales entre virreyes, audiencias, obispos y visitadores, permitieron a los soberanos de la dinastía Habsburgo disponer de ojos celosos que vigilaban de cerca las actuaciones del funcionario o del prelado vecino, así como de manos diligentes que escribían informes y denuncias. No gratuitamente, en casi tres siglos no fue necesario que Sus Católicas Majestades organizaran ejércitos, milicias o cuerpos de policía para mantener en razonable obediencia y sujeción a sus reinos ultramarinos y, sobre todo, a sus dirigentes locales.

En conclusión -y en contra de lo que durante mucho tiempo ha pregonado una historiografía vetusta y acartonada-, nunca en América se cumplió a cabalidad una hipotética voluntad absoluta del rey, ni sus leyes se aplicaron a rajatabla y sin rechistar. En la complicada empresa de mantener unido a un imperio transoceánico y a sus poblaciones variopintas, lo que siempre prevaleció en la Corona fue un deseo de equilibrio, que se materializó, entre las partes implicadas, en la negociación, el arreglo, el regateo y, de ser preciso, inclusive el disimulo.

\section{FuenTES}

Archivo General de Indias, Audiencia de México.

Archivo Histórico Nacional de España.

\section{REFERENCIAS}

Arroyo, L. (1950). Los comisarios generales del Perú. Madrid: CSIC-Instituto Santo Toribio de Mogrobejo.

Arroyo, L. (1952). Comisarios generales de Indias. Archivo Iberoamericano, XII(46), 129-172. 
Bacicalupo, M. A. (1981). A Changing perspective: Attitudes Toward Creole Society in New Spain (1521-1610). London: Tamesis Books Liimited.

Borges Morán, P. (1963). En torno a los comisarios generales de Indias entre las órdenes misioneras de América. Archivo Iberoamericano (23), 145-196.

Borges Morán, P. (1964). En torno a los comisarios generales de Indias entre las órdenes misioneras de América. Archivo Iberoamericano (24), 147-182.

Borges Morán, P. (1965). En torno a los comisarios generales de Indias entre las órdenes misioneras de América. Archivo Iberoamericano (25), 3-61 y 173-221.

Borges Morán, P. (dir.) (1992). Historia de la Iglesia en Hispanoamérica y Filipinas. Siglos XV-XIX, 2 vols. Madrid: Biblioteca de Autores Cristianos.

Ciudad Real, A. (1976). Tratado curioso y docto de las grandezas de la Nueva España. Relación breve y verdadera de algunas cosas de las muchas que sucedieron a padre fray Alonso Ponce en las provincias de la Nueva España siendo comisario general de aquellas partes, 2 vols. México: UNAM-IIH.

García Icazbalceta, J. (ed.) (1892). Códice Mendieta. Documentos franciscanos de los siglos XVI y XVII, 2 vols. México: Imprenta de Francisco Díaz de León (Nueva Colección de Documentos para la Historia de México).

Leal Lobón, M. (2000). La visita de fray Alonso Guerra O.P. a la sede vacante de Michoacán. Isidorianum, 9(18), 465-492.

León Portilla, M. (1999). Bernardino de Sahagún, pionero de la antropología. México: UNAM-IIH-El Colegio Nacional.

Morales Valerio, F. (1973). Ethnic and Social background of the Franciscan friars in the Seventeenth Century Mexico. Washington: Academy of Franciscan History.

Morales Valerio, F. (1988). Criollización de la orden franciscana en Nueva España. Archivo Iberoamericano. Actas del II Congreso Internacional sobre los franciscanos en el Nuevo Mundo (Siglo XVI), 48, (189-192), 661-684.

Ponce (1586). Carta al virrey, 11 de febrero. Archivo General de Indias, Audiencia de México, legajo 2606.

Reyes García, L. (1971). Un nuevo manuscrito de Chimalpahin. Anales del Instituto Nacional de Antropología e Historia, época 7, tomo 2, 333-348.

Ricard, R. (1986). La conquista espiritual de México. Ensayo sobre el apostolado y los métodos misioneros de las órdenes mendicantes en la Nueva España de 1523-1524 a 1572. México: FCE.

Rubial García, A. (1990). Una Monarquía criolla. (La provincia agustina de México en el siglo XVII). México: Consejo Nacional para la Cultura y las Artes.

Rubial García, A. (2001). Votos pactados: las prácticas políticas entre los mendicantes novohispanos. Estudios de Historia Novohispana (26), 51-83.

Rubial García, A. (2010). El paraíso de los elegidos. Una lectura de la historia cultural de Nueva España (1521-1804). México: FCE-UNAM, FFyL.

Ruiz Medrano, E. (1992). Los negocios de un arzobispo: el caso de Montúfar. Estudios de Historia Novohispana, 12(12), 63-83.

Solano, F. (Ed.) (1988). Cuestionarios para la formación de las relaciones geográficas de Indias, siglos XVI-XIX. Madrid: CSIC.

Villamanrique, M.de (1588). Testimonio. Archivo General de Indias, Audiencia de México, legajo 21, núm. 33, f. 1 y ss.

\section{Notas}

1 Que se conservan en el Archivo General de Indias, Audiencia de México, en los legajos 287 y 2606, entre otros.

2 Ha tenido dos ediciones completas: la de Madrid, de 1872 y la de México, de 1976. Amén de reimpresiones de la primera, Madrid, 1873 y otra, facsimilar, editoria Kraus, Nueva York, 1986.

3 Archivo Histórico Nacional de España, Inquisición, v. 1734, exp. 2.

4 Cargos de la visita secreta al virrey marqués de Villamanrique, Archivo General de Indias, 22, n.158.

5 Archivo General de Indias, 1064, L.2, ff. 236v-239r. 